\title{
Assessment of Awareness and Knowledge of Medication Related Osteonecrosis of Jaw among Dental Students at a Tertiary Hospital in Eastern Nepal
}

\author{
Shashi Keshwar, ${ }^{1}$ Deependra Prasad Sarraf, ${ }^{2}$ Ashish Shrestha, ${ }^{1}$ Mehul Rajesh Jaisani, ${ }^{3}$ Sushmita Shrestha ${ }^{4}$ \\ 'Department of Oral Pathology, College of Dental Surgery, ${ }^{2}$ Department of Clinical Pharmacology and Therapeutics, \\ ${ }^{3}$ Department of Oral and Maxillofacial Surgery, College of Dental Surgery, ${ }^{4}$ Department of Conservative Dentistry, College \\ of Dental Surgery, B.P. Koirala Institute of Health Sciences, Dharan, Nepal.
}

\section{ABSTRACT}

\section{Introduction}

The medication related osteonecrosis of jaw (MRONJ) is caused by bisphosphonates, antiresoptive or antiangiogenic drugs. It is the basic requirement for dental students to know the drugs that causing MRONJ and its management. The study was conducted to assess awareness and knowledge of MRONJ among dental students and to compare the mean knowledge score.

\section{Methods}

A cross-sectional study was conducted among dental students at College of Dental Surgery, B. P. Koirala institute of Health Sciences. A semi-structured questionnaires consisting of sociodemographic data and questions regarding awareness and knowledge of MRONJ. Descriptive statistics like mean, standard deviation, percentage and frequency were calculated. Students " $\mathrm{t}$ " test was used for statistical association between the variables at P-value of 0.05 using SPSS.

\section{Results}

Out of 191, 63 (32.98\%) students were aware that drugs other than bisphosphonates can also cause osteonecrosis of jaw while only $16.23 \%$ students were able to name such drugs. Majority of the students (91.62\%) failed to give proper definition of the MRONJ. More than half of the students did not know that invasive dental treatments cannot be given to patients who are currently on oral or intravenous bisphosphonates. Majority (77.5\%) of the students didn't know the treatment guideline for MRONJ. Mean knowledge score of the students was $9.068 \pm 3.092$. There was statistically significant association between the score and age, marital status and academic stream of the students (P-value $<0.05)$.

\section{Conclusions}

The study showed that students had average knowledge and awareness on MRONJ. The knowledge score was statistically associated with age, marital status and educational level. It suggests preeminent steps should be taken to educate future dental students about MRONJ at undergraduate and post graduate level of dentistry.

Key words: Awareness; Dental students; Knowledge; Medication-related osteonecrosis of the jaw.

Correspondence: Dr. Shashi Keshwar, Department of Oral Pathology, College of Dental surgery, B.P. Koirala Institute of Health Sciences, Dharan, Nepal. Email: keshwar.shashi@gmail.com. Phone: +977-981 1833133. 


\section{INTRODUCTION}

The American Association of Oral and Maxillofacial Surgeons has defined Medicationrelated osteonecrosis of jaw (MRONJ) as those presenting with a history of antiresorptive or antiangiogenic drug treatment, the presence of bone exposure or intra- or extraoral fistulization for over eight weeks without remission and no history of radiotherapy or diseases metastasizing to the maxilla. ${ }^{1}$ It is a severe adverse drug reaction to antiresorptive and antiangiogenic drugs. ${ }^{2,3}$ The risk of MRONJ among patients exposed to antiresorptive or antiangiogenic medications ranges from $0.1-6.7 \%{ }^{4}$ The risk factors for MRONJ are tooth extractions, odontogenic inflammatory diseases, trauma by ill-fitted prosthetic dentures, mandibular and palatal tori, corticosteroids, smoking, absorbed dose of the antiresorptive medication and duration of exposure to the drug. ${ }^{5,6}$ The etiology of MRONJ is not completely understood and many hypotheses have been proposed that includes remodeling suppression, osteoclast depression, angiogenesis disruption, and infection. A decrease in angiogenesis is a known contributor to the pathogenesis of osteonecrosis. ${ }^{7}$ The management of MRONJ is problematic and patients do not respond well to the established protocols used for the treatment of MRONJ. Prevention is the key element in dealing with MRONJ. ${ }^{8}$

Dental care providers are more likely to encounter patients who are taking or have taken bisphosphonates and antiangiogenic drugs for osteoporosis, bony metastatic tumors, multiple myeloma, breast cancer and prostate cancer. A working knowledge and awareness of these medications are important for all dental practitioners. Education of dentists, pharmacists, general practitioners and patients about MRONJ is required. ${ }^{9}$ It is crucial to recognize the clinical signs and symptoms of MRONJ, including its radiographic appearance. As MRONJ does not respond well to treatment, it is important to prevent and diagnose the disease early.

Awareness of MRONJ may be a key factor to implement preventative strategies in patients taking or exposed to bisphosphonates or antiangiogenic drugs. Various studies have indicated that awareness and knowledge regarding MRONJ seems to be lacking among dental students and practitioners. ${ }^{9-12}$ Studies on the awareness and knowledge of MRONJ among dental students are very scarce. The detailed knowledge and awareness on occurrence of MRONJ is imperative. Therefore, this study was conducted to assess awareness and knowledge of MRONJ among dental students and to compare the mean knowledge score among undergraduate (UG) and postgraduate (PG) dental students.

\section{METHODS}

A cross-sectional study was conducted among UG and PG dental students between MarchAugust, 2019 at College of Dental Surgery, B.P. Koirala Institute of Health Sciences (BPKIHS), Dharan, Nepal. Sampling Method was population census. A semi-structured proforma was prepared based on the available literature review and used to collect the relevant data on sociodemographic profile, knowledge and on awareness of MRONJ. ${ }^{13,14}$ Age, sex, academic stream were independent variables and mean knowledge score was dependent variable. There were 13 items on awareness (table 2) and 10 items on knowledge related to MRONJ. Score 1 was given for questions answered 'yes' and zero for 'no' or 'do not know' in knowledge section. The knowledge score ranged from 0-18. The knowledge was categorized as good (score 9-18) and poor (score <9). For validation and reliability, the questionnaire was pilot tested among $10 \%$ sample to clarity of the questions and advices from subject experts were also 
taken and those samples were not included in the study. Cronbach's alpha was 0.79 indicating an acceptable level of reliability.

The principal investigator collected the data by visiting to the lecture theaters and individual dental departments. The objectives of the study were explained to the participants and written consent were taken. The proforma was then distributed anonymously and collected immediately within 15 minutes thereby removing false positive answers by discussing with peers or accessing alternative information sources. No personal information were collected to maintain the confidentiality of the participants. Ethical clearance was taken from Institutional Review Committee, BPKIHS (IRC/1474/2018).

The data were rechecked, coded and then entered in Microsoft Excel 2010. Descriptive variables mean, standard deviation (SD), percentage and frequency were calculated. Mean knowledge score was correlated with baseline variables using Student's " $\mathrm{t}$ " test at P-value of 0.05. All statistical analysis was conducted using SPSS version 11.5 .

\section{RESULTS}

Out of 230 students, 191 participated in the study giving a response rate of (83\%). Most of them $(129,67.54 \%)$ were female, unmarried (176, 92.15\%) and aged 20-25 years (152, $79.58 \%)$. One hundred and fifty six students $(81.68 \%)$ were undergraduate (UG) dental students and most of them were in $3^{\text {rd }}$ year. Mean age of the students was 24.05 \pm 2 .63years (Table 1).

Table 1. Sociodemographic characteristics of the participants. $(n=191)$

\begin{tabular}{|l|c|c|c|}
\hline \multicolumn{2}{|c|}{ Variables } & Frequency & Percentage \\
\hline \multirow{3}{*}{ Gender } & Male & 62 & 32.46 \\
\cline { 2 - 4 } & Female & 129 & 67.54 \\
\hline
\end{tabular}

\begin{tabular}{|l|c|c|c|}
\hline \multirow{2}{*}{$\begin{array}{l}\text { Marital } \\
\text { status }\end{array}$} & Married & 15 & 7.85 \\
\cline { 2 - 4 } & Single & 176 & 92.15 \\
\hline $\begin{array}{l}\text { Age group } \\
\text { (years) }\end{array}$ & $20-25$ & 152 & 79.58 \\
\cline { 2 - 4 } & $26-30$ & 35 & 18.32 \\
\cline { 2 - 4 } & $>30$ & 4 & 2.09 \\
\hline \multirow{4}{*}{$\begin{array}{l}\text { Academic } \\
\text { stream }\end{array}$} & (i) Undergraduate & 156 & 81.68 \\
\cline { 2 - 4 } & $3^{\text {rd }}$ year & 56 & 35.9 \\
\cline { 2 - 4 } & $4^{\text {th }}$ year & 38 & 24.36 \\
\cline { 2 - 4 } & $5^{\text {th }}$ year & 33 & 21.12 \\
\cline { 2 - 4 } & Intern & 29 & 18.59 \\
\cline { 2 - 4 } & (ii) Postgraduate & 35 & 18.32 \\
\cline { 2 - 4 } & $1^{\text {st }}$ year & 16 & 45.71 \\
\cline { 2 - 4 } & $2^{\text {nd }}$ year & 10 & 28.57 \\
\cline { 2 - 4 } & $3^{\text {rd }}$ year & 9 & 25.71 \\
\hline
\end{tabular}

Table 2 shows the awareness of MRONJ among the students. Most of the students (133, 69.63\%) were aware of MRONJ; however only 63(33\%) students were aware of the fact that drugs other than bisphosphonates can also cause osteonecrosis of the jaw. More than three forth students $(149,78.0 \%)$ were aware that asking the drug history of bisphosphonates and for antiangiogenic drugs is important before performing invasive dental treatment. More than four fifth students $(158,82.7 \%)$ were aware that patient should be checked and managed for the preexisting dental problems before starting bisphosphonates. More than half of the students did not know that invasive dental treatments cannot be given to patients who are currently on oral or intravenous bisphosphonates or who have taken bisphosphonates for more than 4 years. Majority of students $(188,98.4 \%)$ did not faced medication related osteonecrosis of jaw in their dental practice. Almost three fifth students $(114,59.7 \%)$ had got education on MRONJ and half of them got this education during Bachelor of Dental Surgery (BDS) course. Almost all students $(97.9 \%)$ wanted more education on MRONJ and most of them preferred books 
$(71.7 \%)$ and workshop (64.4\%) (Table 2).

Table 2. Awareness regarding medication related osteonecrosis of jaw. $(n=191)$

\begin{tabular}{|c|c|c|c|c|}
\hline S.N. & Variables & Responses & Frequency & Percentage \\
\hline \multirow[t]{2}{*}{1} & \multirow{2}{*}{$\begin{array}{l}\text { Are you aware of medication related } \\
\text { osteonecrosis of jaw? }\end{array}$} & Yes & 133 & 69.6 \\
\hline & & No & 58 & 30.4 \\
\hline \multirow[t]{2}{*}{2} & \multirow{2}{*}{$\begin{array}{l}\text { Are you aware that drugs other than } \\
\text { bisphosphonates can cause osteonecrosis of jaw? }\end{array}$} & Yes & 63 & 33.0 \\
\hline & & No & 128 & 67.0 \\
\hline \multirow[t]{3}{*}{3} & \multirow{3}{*}{$\begin{array}{l}\text { Do you think that asking the drug history of } \\
\text { bisphosphonates and antiangiogenic drugs } \\
\text { is important before performing invasive } \\
\text { treatment? }\end{array}$} & Yes & 149 & 78.0 \\
\hline & & No & 7 & 3.7 \\
\hline & & Do not know & 35 & 18.3 \\
\hline \multirow[t]{3}{*}{4} & \multirow{3}{*}{$\begin{array}{l}\text { Do you think that patient should be checked } \\
\text { and managed the preexisting dental problems } \\
\text { before starting bisphosphonates? }\end{array}$} & Yes & 158 & 82.7 \\
\hline & & No & 2 & 1.0 \\
\hline & & Do not know & 31 & 16.3 \\
\hline \multirow[t]{3}{*}{5} & \multirow{3}{*}{$\begin{array}{l}\text { Can invasive dental treatments be given } \\
\text { to patients who are currently on oral } \\
\text { bisphosphonates? }\end{array}$} & Yes & 16 & 8.4 \\
\hline & & No & 71 & 37.1 \\
\hline & & Do not know & 104 & 54.5 \\
\hline \multirow[t]{3}{*}{6} & \multirow{3}{*}{$\begin{array}{l}\text { Can invasive dental treatments be given to } \\
\text { patients who are currently on intravenous } \\
\text { bisphosphonates? }\end{array}$} & Yes & 11 & 5.8 \\
\hline & & No & 83 & 43.5 \\
\hline & & Do not know & 97 & 50.7 \\
\hline \multirow[t]{3}{*}{7} & \multirow{3}{*}{$\begin{array}{l}\text { Can invasive dental treatments be given to } \\
\text { patients who have taken bisphosphonates for } \\
\text { more than } 4 \text { years? }\end{array}$} & Yes & 35 & 18.3 \\
\hline & & No & 55 & 28.8 \\
\hline & & Do not know & 101 & 52.9 \\
\hline \multirow[t]{2}{*}{8} & \multirow{2}{*}{$\begin{array}{l}\text { Have you ever faced medication related } \\
\text { osteonecrosis of jaw in your dental practice? }\end{array}$} & Yes & 3 & 1.6 \\
\hline & & No & 188 & 98.4 \\
\hline \multirow[t]{2}{*}{9} & \multirow{2}{*}{$\begin{array}{l}\text { Have you received any education on medication } \\
\text { related osteonecrosis of jaw? }\end{array}$} & Yes & 114 & 59.7 \\
\hline & & No & 77 & 40.3 \\
\hline \multirow[t]{4}{*}{10} & \multirow[t]{4}{*}{ You got the education on MRONJ through: } & Taught during BDS course & 113 & 59.2 \\
\hline & & Seminar & 54 & 28.3 \\
\hline & & Continuing Dental Education & 7 & 3.7 \\
\hline & & Education within workplace & 6 & 3.1 \\
\hline \multirow[t]{2}{*}{11} & \multirow{2}{*}{$\begin{array}{l}\text { Are you aware of the guidelines for medication } \\
\text { related osteonecrosis of jaw treatment? }\end{array}$} & Yes & 43 & 22.5 \\
\hline & & No & 148 & 77.5 \\
\hline \multirow[t]{2}{*}{12} & \multirow{2}{*}{$\begin{array}{l}\text { Would you like to learn more about medication } \\
\text { related osteonecrosis of jaw? }\end{array}$} & Yes & 187 & 97.9 \\
\hline & & No & 4 & 2.1 \\
\hline \multirow[t]{8}{*}{13} & \multirow{8}{*}{$\begin{array}{l}\text { What would be your preference for continuing } \\
\text { to learn about medication related osteonecrosis } \\
\text { of jaw? }\end{array}$} & Books & 137 & 71.7 \\
\hline & & Workshop & 123 & 64.4 \\
\hline & & Journals & 109 & 57.1 \\
\hline & & seminar & 43 & 22.5 \\
\hline & & $\begin{array}{l}\text { Structured Interactive } \\
\text { Session }\end{array}$ & 9 & 4.7 \\
\hline & & internet & 5 & 2.6 \\
\hline & & Case Based Learning & 2 & 1 \\
\hline & & Continued Dental Education & 1 & 0.5 \\
\hline
\end{tabular}


The knowledge score ranged from 2 to 16 . Only 112 students $(58.6 \%)$ scored more than $50 \%$ of total knowledge score (Figure 1). mean knowledge score of students having age more than 25 years (mean=11.74, SD=2.79) was statistically higher than the students having age

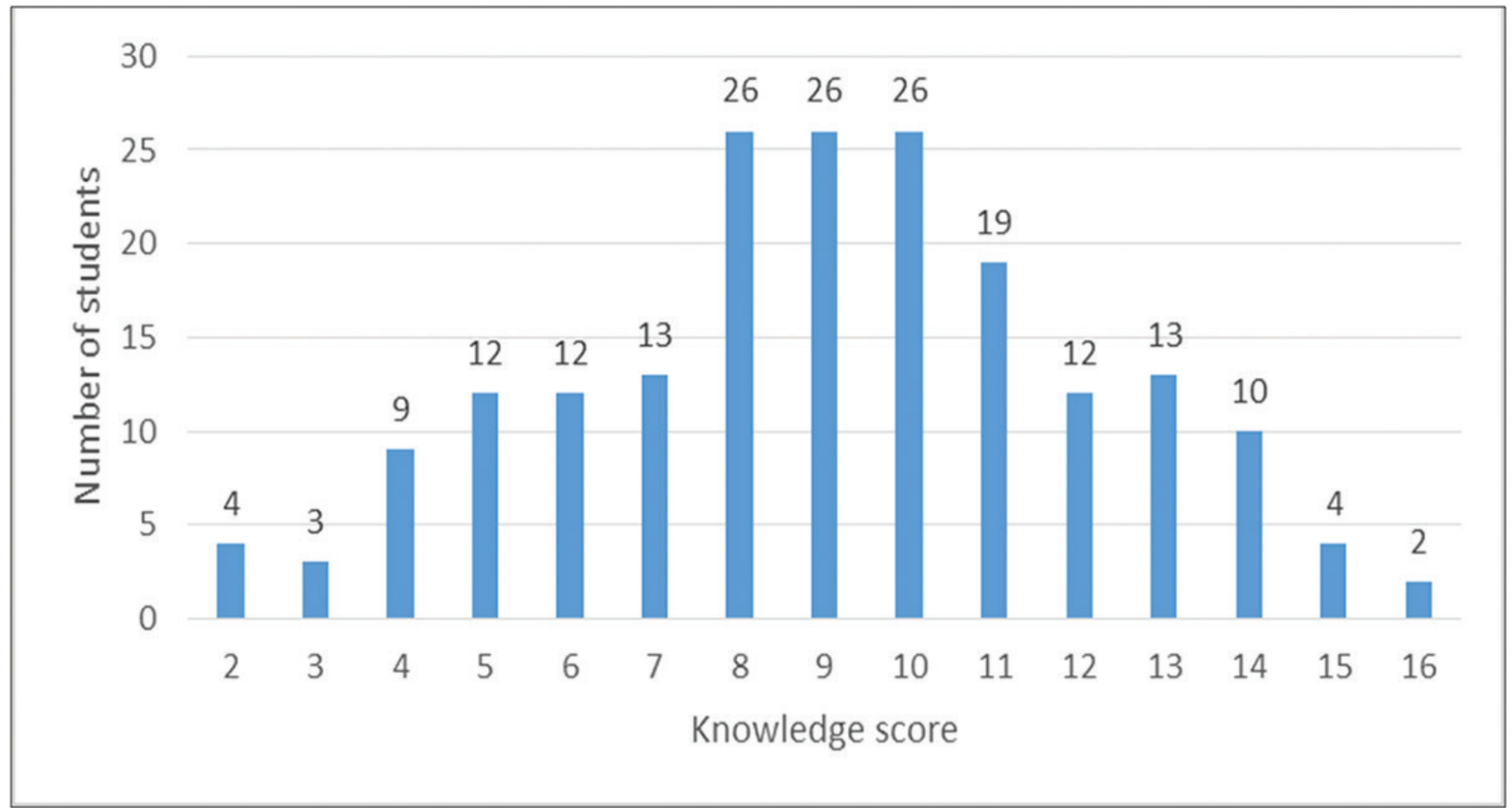

Figure 1. Knowledge score of the students $(n=191)$

Mean knowledge score of all students was 9.068 \pm 3.092 . Out of 191, $112(58.6 \%)$ students scored $50 \%$ and above while $79(41.4 \%)$ students scored less than $50 \%$ of maximum score. The up to 25 years (mean=8.41, SD=2.820) (t (189) $=6.334, \mathrm{P}=000, \mathrm{~d}=1.14)$. Similarly, the mean knowledge score of postgraduate students (mean=11.77, SD=2.723) was statistically higher than the undergraduate students (mean=8.46,

Table 4. Knowledge score of the students. $(n=191)$

\begin{tabular}{|c|c|c|c|c|c|c|c|}
\hline \multirow[t]{2}{*}{ S. N. } & \multirow{2}{*}{\multicolumn{2}{|c|}{ Variables }} & \multirow{3}{*}{$\begin{array}{l}\text { Mean score } \pm \\
\text { Standard Deviation } \\
\text { Upper limit } \\
9.37 \pm 3.305\end{array}$} & \multicolumn{2}{|c|}{$\begin{array}{c}95 \% \text { Confidence Interval } \\
\text { of mean score }\end{array}$} & \multirow[t]{2}{*}{ P-value } & \multirow[t]{2}{*}{ Cohen's o } \\
\hline & & & & Lower limit & & & \\
\hline \multirow{2}{*}{1.} & \multirow{2}{*}{ Gender } & Male & & 8.53 & 10.21 & \multirow{2}{*}{0.346} & \multirow{2}{*}{--} \\
\hline & & Female & $8.92 \pm 2.986$ & 8.40 & 9.44 & & \\
\hline \multirow{2}{*}{2} & \multirow{2}{*}{$\begin{array}{l}\text { Age group } \\
\text { in years }\end{array}$} & Up to 25 & $8.41 \pm 2.820$ & 7.96 & 8.87 & \multirow{2}{*}{$0.000 *$} & \multirow{2}{*}{1.14} \\
\hline & & $>25$ & $11.62 \pm 2.797$ & 10.71 & 12.52 & & \\
\hline \multirow{2}{*}{3.} & \multirow{2}{*}{$\begin{array}{l}\text { Marital } \\
\text { status }\end{array}$} & Married & $11.87 \pm 2.924$ & 10.25 & 13.49 & \multirow{2}{*}{$0.000 *$} & \multirow{2}{*}{1.02} \\
\hline & & Single & $8.83 \pm 2.994$ & 8.38 & 9.27 & & \\
\hline \multirow{2}{*}{4.} & \multirow{2}{*}{$\begin{array}{l}\text { Academic } \\
\text { stream }\end{array}$} & Undergraduate & $8.46 \pm 2.841$ & 8.01 & 8.91 & \multirow{2}{*}{$0.000 *$} & \multirow{2}{*}{1.89} \\
\hline & & Postgraduate & $11.77 \pm 2.723$ & 10.84 & 12.71 & & \\
\hline
\end{tabular}

*Statistically significant at P-value less than 0.05 (Students $t$ test) 
$\mathrm{SD}=2.841)(\mathrm{t}(189)=6.276, \mathrm{P}=000, \mathrm{~d}=1.89)($ Table 4).

\section{DISCUSSION}

The increase in cases of MRONJ has indicated an imminent need for dentist to have a broad and consolidate knowledge about prevention, early detection and special management. Our study was performed with the aim to assess the knowledge and awareness of dentist about MRONJ. Most of the students were female and similar finding is also reported by Rosella et al. ${ }^{15}$ Mean age of the students was 24.05 years and in contrast to this finding a lower mean age was reported by Rosella et al. ${ }^{15}$ This was due to inclusion of PG students in our study. More than two third students $(69.6 \%)$ were aware of medication related osteonecrosis of jaw. This is inconsistent with Park et al who reported that only $56.5 \%$ of Korean dentists were aware of MRONJ. ${ }^{12}$ Efforts to increase the awareness of MRONJ among dental students and practitioner is necessary emphasizing the importance of prevention of the disease. Approximately two third of the students were unaware that drugs other than bisphosphonates can also cause osteonecrosis of jaw. This is inconsistent with another study that identified that lesser number (55\%) of the participants were unaware of any other drugs aside from bisphosphonates that could lead to the development of osteonecrosis of jaw. ${ }^{10}$ This might be due to their study population that included dental practitioner who had more years of experiences. It remains important for dental surgeon to be aware of antiangiogenic and antiresorptive drugs implicated in MRONJ as the number of these agents being prescribed is increasing and hence they are more likely to come across patients taking them.

Majority of the students failed to give proper definition of the MRONJ. In contrast to this majority of the participants gave a correct definition of osteonecrosis of the jaw stating 'dead bone' or 'death of bone' in a study conducted by Tanna et al. ${ }^{10}$ Awareness of the definition of osteonecrosis and identification of 'at risk' patients is important for dental surgeon. More than three forth students were aware that asking the drug history of bisphosphonates and antiangiogenic drugs is important before performing invasive dental treatment. In contrast to this finding, only one third of Korean dentists used to ask antiresorptive drugs in patient medical history prior to surgery. ${ }^{16}$ More than four fifth students were aware that patient should be checked and managed for the preexisting dental problems before starting bisphosphonates. Before starting administration of anti-resorptive for the treatment of osteoporosis, physicians need to explain to patients the benefits of anti-resorptive for bone metastases and osteoporosis, risks of antiresorptive for MRONJ. It is wise to request patients to visit a dentist to control oral health to prevent the occurrence of MRONJ. All dental treatments should be completed two weeks before starting anti-resorptive treatment. ${ }^{17}$ Patients should also be advised to maintain good levels of oral hygiene and to undergo regular dental check-ups (e.g. every 6 months) during treatment. ${ }^{18}$

More than half of the students did not know that invasive dental treatments cannot be given to patients who are currently on oral or intravenous bisphosphonates or who have taken bisphosphonates for more than 4 years. Similar findings is also reported by Yoo et al. ${ }^{16}$ These findings describes the state of urgency in educating dentists about MRONJ. Majority of students had got education on MRONJ and half of them got this education during BDS course. Bisphosphonate is taught during BDS course as per the curriculum of the BPKIHS. There should be a separate module on MRONJ in phase 2 of BDS to make the students more aware on it. Almost all students wanted more education on MRONJ and most of them preferred books and 
workshop. This is in consistent with the finding of Rosella et al. ${ }^{15}$ The study suggests that there is a need for further education and regular update on MRONJ for dental students. The knowledge on MRONJ is found to be good only in three-fifth of the students. Out of 5 students, two had poor knowledge regarding MRONJ. The students aged more, married and PG scored more compared to the aged less, unmarried and UG students. The PG students have more experience as compared to the UG and hence they have high score. There is need of further education to young dental graduates through educational campaigns, seminar, workshop and lecture in collaboration with local dental association, state and national bodies to increase their knowledge about MRONJ.

Our study have some limitations. The study was limited to the UG and PG dental students at one college and hence any generalization to the

\section{REFERENCES}

1. SL Ruggiero, TB Dodson, J Fantasia. American association of oral and maxillofacial surgeons position paper on medication-related osteonecrosis of the jaw-2014 update. J Oral Maxillofac Surg. 2014; 72(10):1938-56.

2. Kununya Pimolbutr, Stephen Porter, Stefano Fedele. Osteonecrosis of the Jaw Associated with Antiangiogenics in Antiresorptive-Naïve Patient: A Comprehensive Review of the Literature. Biomed Res Int. 2018;2018: 8071579.

3. Diniz-Freitas $M$, Fernández-Feijoo J, Diz Dios P, Pousa X, Limeres J. Denosumabrelated osteonecrosis of the jaw following non-surgical periodontal therapy: A case report. J Clin Periodontol. 2018;45(5):5707. students of other colleges may be inappropriate. The study was based on a self-reported questionnaire inducing an inconsistency between students' self-reported and actual awareness and knowledge.

\section{CONCLUSIONS}

The study showed that the knowledge and awareness on MRONJ among the students was not upto the standard level. It highlighted the importance of further education to increase the awareness and knowledge of MRONJ among the students. It also suggests that preeminent steps should be taken to educate future dentists about MRONJ at undergraduate and post graduate dental students.

\section{ACKNOWLEDGEMENTS}

We would like to thank the participants who generously gave their valuable time to the survey.

4. Dodson TB. The Frequency of Medication-related Osteonecrosis of the Jaw and its Associated Risk Factors. Oral Maxillofac Surg Clin North Am. 2015;27(4):509-16.

5. McGowan K, McGowan T, Ivanovski S. Risk factors for medication-related osteonecrosis of the jaws: A systematic review. Oral Dis. 2018;24(4):527-36.

6. S Ruggiero, D Saxena, S Tetradis, T Aghaloo, E Ioannidou. Task Force on Design and Analysis in Oral Health Research: Medication-Related Osteonecrosis of the Jaw. JDR Clinical \& Translational Research. 2018;3(3):222-5.

7. Eid A, Atlas J. The role of bisphosphonates in medical oncology and their association with jaw bone necrosis. Oral Maxillofac Surg Clin North Am. 2014;26(2):231-7. 
8. Hutcheson A, Cheng A, Kunchar R, Stein B, Sambrook P, Goss A. A C-terminal crosslinking telopeptide test-based protocol for patients on oral bisphosphonates requiring extraction: a prospective single-center controlled study. J Oral Maxillofac Surg. 2014;72:1456-62.

9. Gaudin E, Seidel L , Bacevic M , Rompen E , Lambert F. Occurrence and risk indicators of medicationrelated osteonecrosis of the jaw after dental extraction: a systematic review and meta-analysis. J Clin Periodontol. 2015;42(10):922-32.

10. Tanna N, Steel C, Stagnell S, Bailey E. Awareness of medication related osteonecrosis of the jaws (MRONJ) amongst general dental practitioners. $\mathrm{Br}$ Dent J. 2017;222(2):121-5.

11. Vinitzky-Brener I, Ibáñez-Mancera NG, Aguilar-Rojas AM, Álvarez-Jardón AP. Knowledge of bisphosphonate-related osteonecrosis of the Jaws among Mexican dentists. Med Oral Patol Oral Cir Bucal. 2017;22(1):e84-e87.

12. Park YD, Kim YR, Kim DY et al. Awareness of Korean dentists on bisphosphonate related osteonecrosis of the jaws: preliminary report. J Korean Assoc Oral Maxillofac Surg. 2009;35: 1537.

13. Ruggiero SL, Mehrotra B, Rosenberg TJ.
Osteonecrosis of the jaws associated with the use of bisphosphonates: a review of 63 cases. J Oral Maxillofac Surg. 2004;62:527-34.

14. Park WS, Chung WY, Kim HJ, Kim KD. Considerations during dental implant treatment for patients under bisphosphonate therapy. J Korean Dent Assoc. 2011;49:389-97.

15. Rosella D, Papi P, Pompa G, Capogreco M, De Angelis F, Di Carlo S. Dental students' knowledge of medicationrelated osteonecrosis of the jaw. Eur J Dent. 2017;11(4):461-8.

16. Yoo JY, Park YD, Kwon YD, Kim DY, Ohe JY. Survey of Korean dentists on the awareness of bisphosphonate-related osteonecrosis of the jaws. J Investig Clin Dent. 2010;1:90-5.

17. Dhesy-Thind S, Fletcher GG, Blanchette PS, etal.Useof adjuvantbisphosphonates and other bone-modifying agents in breast cancer: a Cancer Care Ontario and American Society of Clinical Oncology Clinical Practice Guideline. J Clin Oncol. 2017;35:2062-81.

18. Nicolatou-Galitis O, Schiødt M, Mendes RA, Ripamonti C, Hope S, DrudgeCoates L, et al. Medication-related osteonecrosis of the jaw: definition and best practice for prevention, diagnosis, and treatment. Oral Surg Oral Med Oral Pathol Oral Radiol. 2019;127(2):117-35.

Citation: Keshwar S, Sarraf D, Shrestha A, Jaisani M, Shrestha M. Assessment of Awareness and Knowledge of Medication Related Osteonecrosis of Jaw Among Dental Students at a Tertiary Hospital in Eastern Nepal. JCMS Nepal. 2021; $7(1)$; $36-43$. 